\title{
Response surface methodology for the optimization of detection of flavor components in tobacco using simultaneous distillation extraction
}

\author{
Xueqin $\mathrm{Xu}^{1}$, Xiaolan $\mathrm{Li}^{1}$,a, Shansong Huang ${ }^{1}$, Yun Zhou ${ }^{1}$, Haijiang $\mathrm{Jia}^{1}$ and Xiaoming $\mathrm{Li}^{2}$ \\ ${ }^{1}$ Technology Center, China Tobaco Guangxi Industrial Co, Ltd, Nanning 530001, China \\ ${ }^{2}$ College of Environmental Science and Engineering, Hunan University, Changsha 410082, China
}

\begin{abstract}
Flavor components are quite important for the quality of tobacco, however, the detection of flavor component is always limited the existing technology and changeable environment. Previous literatures reported simultaneous distillation extraction (SDE) technology was an efficient approach for the detection of flavor components. The optimal parameters for flavor components detection are poorly determined since their test conditions are quite different. In this study, the key factors, e.g., the ratio of material to solution, distillation time, the ratio of $\mathrm{NaCl}$ dosage to tobacco, the ratio of $\mathrm{CH} 2 \mathrm{Cl} 2$ to tobacco, and bath temperature, affecting extraction amount of flavoring substances were fully discussed. Furthermore, response surface methodology is employed to optimum operating conditions for SDE, and the optimal results are as follows: the ratio of material to liquid was $1: 12$, the distillation time was $3.23 \mathrm{~h}$, the ratio of $\mathrm{NaCl}$ dosage to tobacco was $1.05: 1$, the ratio of $\mathrm{CH} 2 \mathrm{Cl} 2$ to tobacco was 1.92 , the bath temperature was $60{ }^{\circ} \mathrm{C}$, and the amount of extraction of flavoring substances was $2.39 \mathrm{mg} / \mathrm{g}$. This work might provide an instructive significance for engineering to detect the content of flavor components in tobacco.
\end{abstract}

\section{Introduction}

Tobacco, a special crops, has made great contributions to our finance and economic development. However, the tobacco also contains harmful substances, such as tobacco tar, nicotine, phenols, which could cause great influence on the health of smokers. Many countries have developed advanced technologies to reduce the harmful substance in tobacco. The reduction of harmful substance inevitably reduces the content of flavor component, which is an great factor for the quality of tobacco. Therefore, adding flavor component is an efficient approach to achieve high quality of tobacco and low levels of harmful substance, simultaneously [1-3].

The extraction and detection of the flavor components are the first step to understand the nature of spices and regulate of the aroma of cigarettes. The general detection methods contain dynamic headspace, micro-distillation and extraction, headspace co-distilled, and simultaneous distillation extraction (SDE) [4, 5]. Among those methods, the application of SDE has drawn great attentions for its simple operation and high extraction efficiency. SED is an extraction, separation and enrichment of plant samples approach, the method integrated extraction, distillation with extraction in one step [6, 7]. SDE always serves as pretreatment for detection and analysis of volatile and semi-volatile components in food, tobacco and flavors and fragrances. There are two processing units i.e., extraction and concentration in SDE, which makes its operation simple. Previous studies have applied SDE for the extraction of volatile flavoring substances in tobacco and other plant [8]. However, the comparative of those results are rather poor since their test conditions are quite different, which can not meet the current research needs ().

Response surface methodology (RSM) is a commonly used approximate model [9-11], and the optimal parameters can be obtained by analyzing the regression equation. RSM has the characteristics of high precision and predictability, which has been widely applied to optimize experimental data in the fields of agriculture, biotechnology, food and chemical [12-14]. However, few publications investigated the optimization of tobacco test data using RSM, which limits the development of tobacco testing [15].

Therefore, the aim of this work is to investigate the optimum operating conditions for SDE using RSM, and further investigate extraction efficiency and stability under the operating conditions. This study will provide a theoretical basis for detection of tobacco flavor components.

\section{Materials and equipment}

\subsection{Experimental material, main instruments and equipments}

The tobacco material used in this work was collected from Guangxi Tobacco. Chinese herbal medicine grinder:

a Corresponding author: xiaolan-dg@163.com 
FW135; Electronic balance: EL204; Digital thermostat water bath: HH-4; Cryogenic coolant circulation pump: KPGD5/20; Adjustable electric sets: KDM-1000; Gas chromatography-mass spectrometer: Agilent 7890GC/5975MS; Electric oven blast: DHG-9145A, and Simultaneous distillation and extraction device was made in Zhengzhou Technological Glass Instrument Factory.

Extraction solvent is an important factor affecting the detection accuracy of volatile flavor components in tobacco, and especially when the test substance was concentrated, the concentration of impurity can reach hundreds even thousands fold of that in the raw test substance, causing huge interference on determination of volatile flavor components in tobacco. $\mathrm{CH}_{2} \mathrm{Cl}_{2}$ is always selected as extraction solvent, and its purity could affect the results of detection. Thus, we first choose four samples i.e, analytical grade, domestic chromatography grade, imports $1 \mathrm{\#}$, and Dikma to test their influence on the results of detection. $100 \mathrm{~mL}$ of $\mathrm{CH}_{2} \mathrm{Cl}_{2}$ was concentrated to $1.0 \mathrm{~mL}$ and then transported for GC-MS analysis, and the results are displayed in Figure 1.

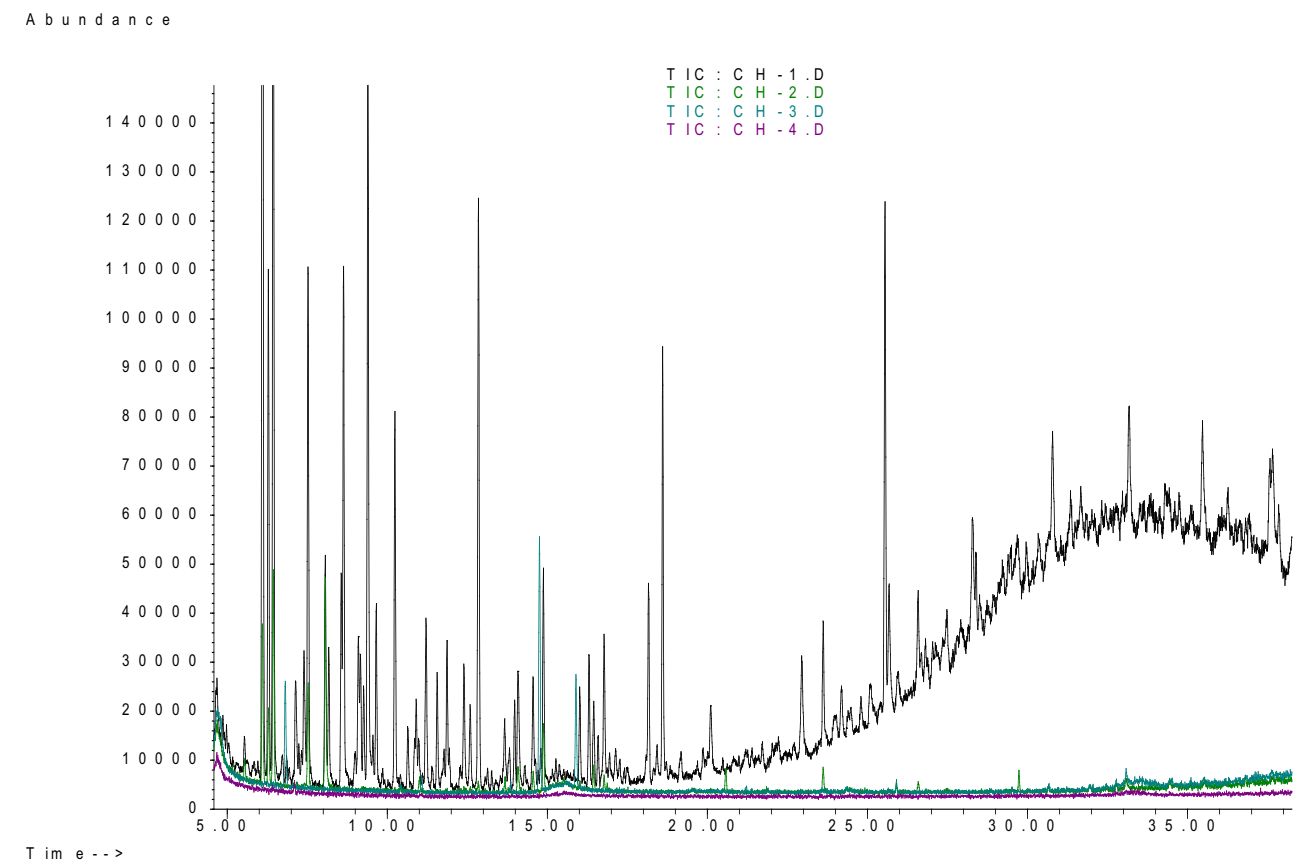

Figure 1. Total ion current chromatogram with different kinds of $\mathrm{CH}_{2} \mathrm{Cl}_{2}(\mathrm{CH}-1=$ Domestic analysis pure; $\mathrm{CH}-2=$ Domestic chromatographic purity; $\mathrm{CH}-3=$ Imported1\#; $\mathrm{CH}-4=$ Dikma).

As shown in Figure 1, there is almost no peaks in the total ion chromatogram when the test substance was pretreated with Dikma $\mathrm{CH}_{2} \mathrm{Cl}_{2}$, and the baseline is relatively stable. Although there were several miscellaneous peaks when the time was $40 \mathrm{~min}$, and their presence posed little influence on the detection result. However, there are many miscellaneous peaks in the total ion chromatogram and the baselines are unstable when treated with other kinds of $\mathrm{CH}_{2} \mathrm{Cl}_{2}$. From the above discussion, the Dikma $\mathrm{CH}_{2} \mathrm{Cl}_{2}$ was selected as the extracting agent for the determination of volatile flavor components in tobacco.

\subsection{Optimization study of SDE}

Before the experiment, $350 \mathrm{~mL}$ of distilled water $(\mathrm{pH}=7.0)$ and $60 \mathrm{~mL}$ of $\mathrm{CH}_{2} \mathrm{Cl}_{2}$ were added into the two sides of $\mathrm{SDE}$ for $2.5 \mathrm{~h}$ to clean equipment.

$30 \mathrm{~g}$ of tobacco dust samples was added into round-bottomed flask $(1000 \mathrm{~mL})$ in one side of the SDE and then appropriate amount of sodium chloride and distilled water were also added. The temperature was maintained by temperature electric sets. On the other side of the SDE, a concentrated bottle with $\mathrm{CH}_{2} \mathrm{Cl}_{2}$ was set.
After certain time for simultaneous distillation extraction, $1.0 \mathrm{~mL}$ of internal standard ethyl acetate solution $(0.4237$ $\mathrm{mg} / \mathrm{mL}$ ) was added and then concentrated into $1.0 \mathrm{~mL}$ for the analysis of GC-MS.

\subsection{Analytical conditions of GC-MS}

The main equipments used in this work were GC and GC-MS, the analytical conditions of GC-MS are as follows:

1. Chromatographic conditions: Column: HP-5MS (60 $\mathrm{m} \times 0.25 \mathrm{~mm}$ i.d. $\times 0.25 \mu \mathrm{m}$ d.f.); Inlet temperature: $280^{\circ} \mathrm{C}$; Injection volume: $1 \mu \mathrm{L}$; Split ratio: $10: 1$; carrier gas: $\mathrm{He}, 1.0 \mathrm{~mL} / \mathrm{min}$.

2. MS conditions: Transfer line temperature: $280{ }^{\circ} \mathrm{C}$; EI electron energy source: $70 \mathrm{eV}$; Electron multiplier voltage: $1635 \mathrm{~V}$; Mass scan range: $30 \sim 550 \mathrm{amu}$; Ion source temperature: $230{ }^{\circ} \mathrm{C}$.

The total ion chromatogram shown in Figure 2 is under the experimental conditions described above. As shown in Figure 2, peak shape is good and it can meet the requirements of analysis. 


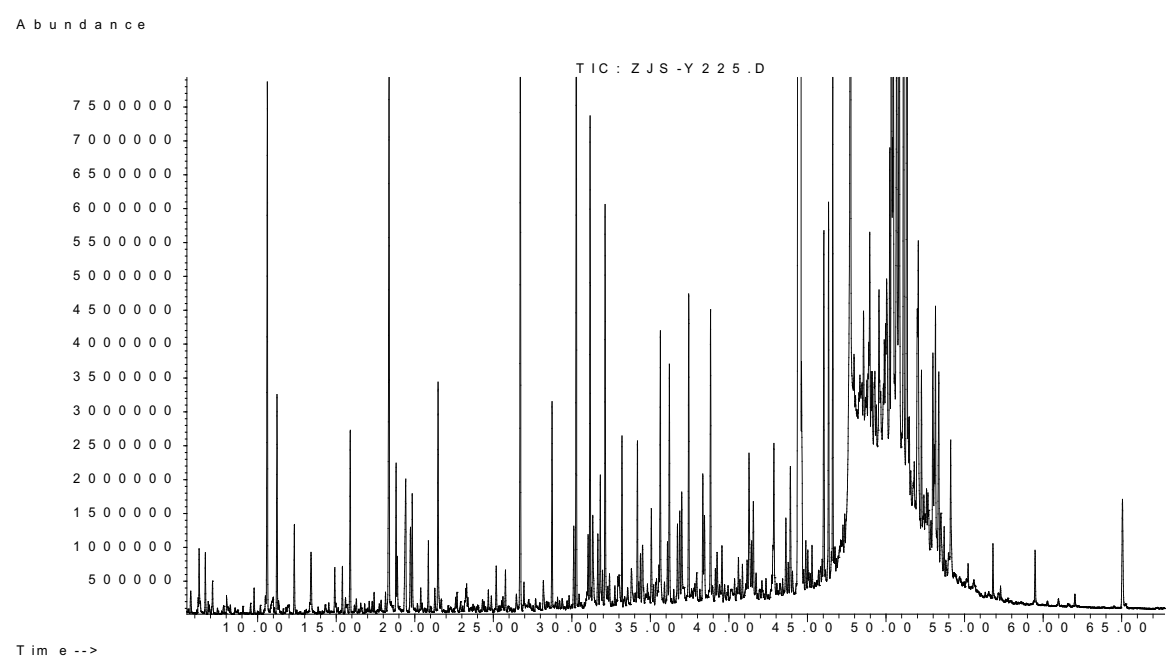

Figure 2. Total ion current chromatogram of tobacco aroma substances.

\section{Results and discussion}

\subsection{Single factor experiment of simultaneous distillation and extraction}

There are many researches on the extraction of plant flavoring substances using SDE, while those researches are based on different experimental conditions, and the results are also quite different. Thus, we first optimized the experimental conditions about SDE.

\subsubsection{Effect of the ratio of material to solution on the extraction amount of flavoring substances}

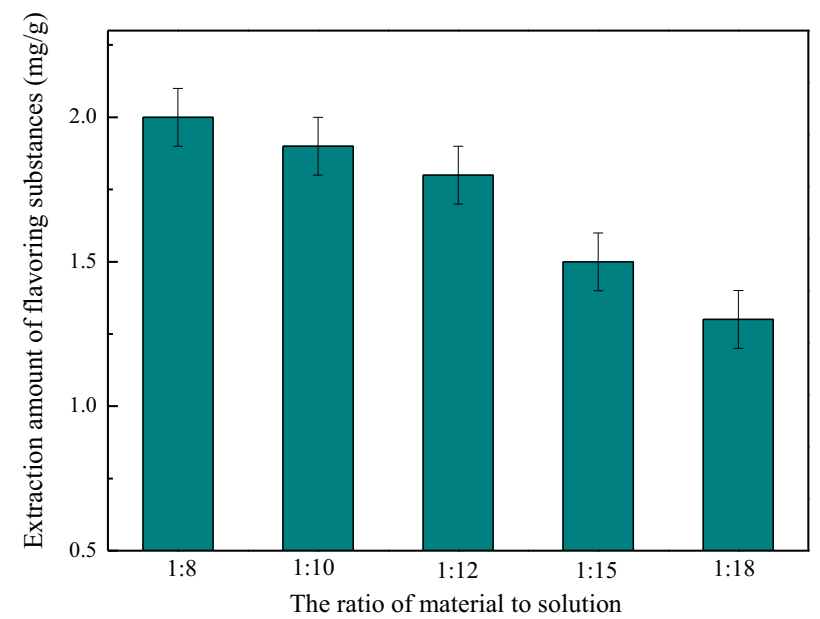

Figure 3. Effect of the ratio of material to solution on the extraction amount of flavoring substances. Error bars represent standard deviations of triplicate tests.

The ratio of material to solution is an important factor affecting the extraction amount of flavoring substances. In this batch test, the ratio of material to solution on the extraction amount of flavoring substances was assessed and the result was displayed in Figure 3. As shown in Figure 3, increase of the ratio of material to solution posed a negative effect on the extraction amount of flavoring substances, for example, when the ratio of material to solution increased from $1: 8$ to $1: 18$, the extraction amount of flavoring substances decreased from 2.0 to $1.6 \mathrm{mg} / \mathrm{g}$. This phenomenon can be ascribed to the increase of content of water. The increase of water content could certainly increased the amount of dissolved flavoring substances, thereby causing the decrease of extraction amount of flavoring substances by SDE. However, the low level of water content would cause pasting, which is detrimental to extraction of flavoring substances. Therefore, the suitable ratio of material to solution was determined at 1:12 (Figure 3).

\subsubsection{Effect of distillation time on the extraction amount of flavoring substances}

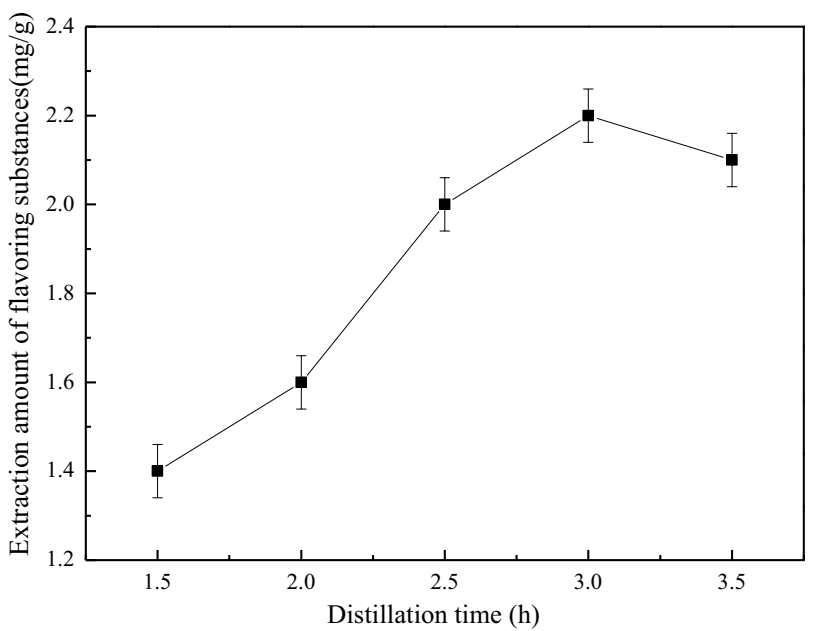

Figure 4. Effect of distillation time on the extraction amount of flavoring substances. Error bars represent standard deviations of triplicate tests.

Figure 4 shows the effect of distillation time on the extraction amount of flavoring substances. It was found that the extend of distillation time from 1.5 to $3 \mathrm{~h}$ would improve the extraction amount of flavoring substances from 1.4 to $2.2 \mathrm{mg} / \mathrm{g}$. However, further increase of distillation time to $3.5 \mathrm{~h}$, the extraction amount of flavoring substances decreased to $2.1 \mathrm{mg} / \mathrm{g}$. The reason 
for this phenomenon might be that some kinds of flavoring substances was not stable, and long distillation time could cause flavoring substance's decomposition, oxidation or hydrolysis, however, short distillation time would cause incomplete extraction. Thus, the optimal distillation time was $3 \mathrm{~h}$.

\subsubsection{Effect of $\mathrm{NaCl}$ dosage on the extraction amount of flavoring substances}

In this batch test, the effect of $\mathrm{NaCl}$ dosage on the the extraction amount of flavoring substances was investigated and the result was shown in Figure 5. It was found that the increase of the ratio of $\mathrm{NaCl}$ dosage to tobacco from 0 to $1: 1$, the extraction amount of flavoring substances also increased from 1.5 to $2.2 \mathrm{mg} / \mathrm{g}$, however, further increase of the ratio of $\mathrm{NaCl}$ dosage to tobacco posed a negative effect on the extraction amount of flavoring substances. Thus, the optimal the ratio of $\mathrm{NaCl}$ dosage to tobacco was $1: 1$.

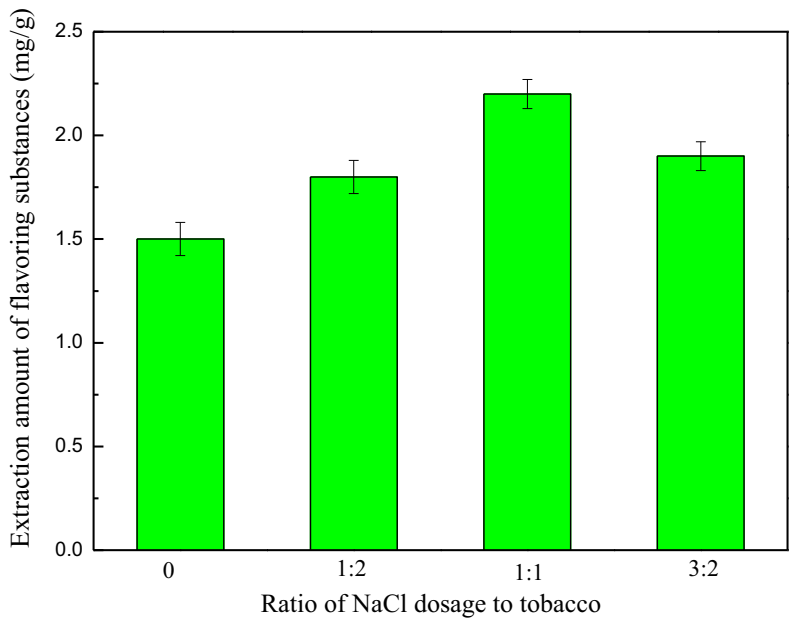

Figure 5. Effect of the ratio of $\mathrm{NaCl}$ dosage to tobacco on the extraction amount of flavoring substances. Error bars represent standard deviations of triplicate tests.

\subsubsection{Effect of the volume of $\mathrm{CH}_{2} \mathrm{Cl}_{2}$ on the extraction amount of flavoring substances}

The volume of $\mathrm{CH}_{2} \mathrm{Cl}_{2}$ is also an important factor affecting the extraction amount of flavoring substances. Figure 6 exhibited the effect of the volume of $\mathrm{CH}_{2} \mathrm{Cl}_{2}$ on the extraction amount of flavoring substances. As shown in Figure 6, when the ratio of $\mathrm{CH}_{2} \mathrm{Cl}_{2}$ to tobacco was 2:1, the extraction amount of flavoring substances achieved its highest value.

\subsubsection{Effect of bath temperature on the extraction amount of flavoring substances}

This batch test assessed the effect of bath temperature on the extraction amount of flavoring substances, and the bath temperature was controlled at $50^{\circ} \mathrm{C}, 55^{\circ} \mathrm{C}, 60^{\circ} \mathrm{C}$, $65^{\circ} \mathrm{C}, 70^{\circ} \mathrm{C}$. As shown in Figure 7 , the increase of bath temperature from $50^{\circ} \mathrm{C}$ to $60{ }^{\circ} \mathrm{C}$ enhanced the extraction amount of flavoring substances from 1.6 to $2.1 \mathrm{mg} / \mathrm{g}$.
However, further increase of temperature to $70{ }^{\circ} \mathrm{C}$ decreased the extraction amount of flavoring substances. The increase of bath temperature could improve the evaporation rate of $\mathrm{CH}_{2} \mathrm{Cl}_{2}$, meanwhile the evaporation rate of aqueous phase is constant, thereby causing the sufficient extraction of organic phase.

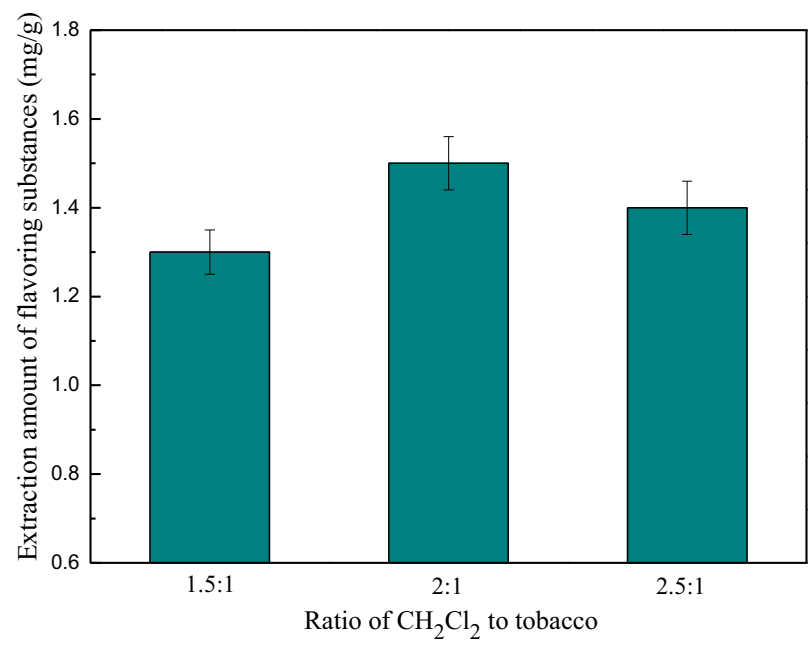

Figure 6. Effect of the ratio of $\mathrm{CH}_{2} \mathrm{Cl}_{2}$ to tobacco on the extraction amount of flavoring substances. Error bars represent standard deviations of triplicate tests.

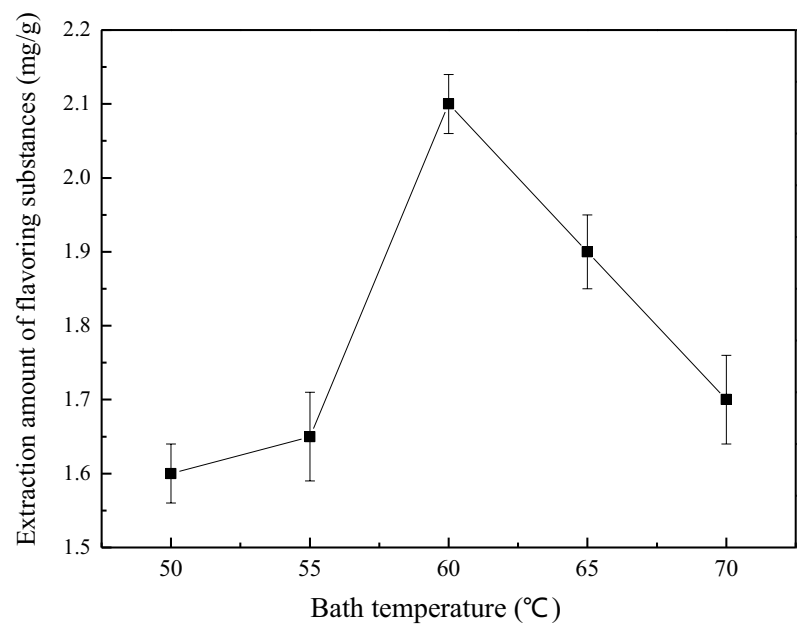

Figure 7. Effect of bath temperature on the extraction amount of flavoring substances. Error bars represent standard deviations of triplicate tests.

\subsection{Optimization of experimental conditions using response surface methodology}

Based on the results of five single factor experiment i.e., A-the ratio of material to solution, B- distillation time, C-the ratio of $\mathrm{NaCl}$ dosage to tobacco, D- the ratio of $\mathrm{CH}_{2} \mathrm{Cl}_{2}$ to tobacco, and E-bath temperature, to determine the level range of each factor of the response surface test, and the factors and levels of response surface were shown in Table 1 .

Design-Expert was applied to design the response surface experiment, and the model of Box-Behnken was also employed to design orthographic quadratic regression test, the results were shown in Table 2. 
Table 1. Response surface experimental factor level and coding table.

\begin{tabular}{cccccc}
\hline & $\begin{array}{c}\text { Ratio of material } \\
\text { to solution }(\mathrm{g} / \mathrm{mL})\end{array}$ & $\begin{array}{c}\text { Distillation } \\
\text { time/h }\end{array}$ & $\begin{array}{c}\text { Ratio of } \mathrm{NaCl} \text { dosage } \\
\text { to tobacco }(\mathrm{g} / \mathrm{g})\end{array}$ & $\begin{array}{c}\text { Ratio of } \mathrm{CH}_{2} \mathrm{Cl}_{2} \text { to tobacco } \\
(\mathrm{mL} / \mathrm{g})\end{array}$ & $\begin{array}{c}\text { Bath } \\
\text { temperature } /{ }^{\circ} \mathrm{C}\end{array}$ \\
\hline-1 & $1: 10$ & 2.5 & $0.8: 1$ & $1.8: 1$ & 55 \\
0 & $1: 12$ & 3 & $1: 1$ & $2: 1$ & 60 \\
1 & $1: 14$ & 3.5 & $1.2: 1$ & $2.2: 1$ & 65 \\
\hline
\end{tabular}

Table 2. The design and results of Box- Behnken experiment.

\begin{tabular}{|c|c|c|c|c|c|c|}
\hline \multirow{2}{*}{ No } & \multicolumn{5}{|c|}{ Factors } & \multirow{2}{*}{ Extraction $(\mathrm{mg} / \mathrm{g})$} \\
\hline & A & $\mathrm{B}$ & $\mathrm{C}$ & $\mathrm{D}$ & $\mathrm{E}$ & \\
\hline 1 & 0 & 1 & 0 & 0 & 1 & 2.03 \\
\hline 2 & 0 & 0 & -1 & 0 & -1 & 1.82 \\
\hline 3 & 0 & -1 & 0 & -1 & 0 & 1.82 \\
\hline 4 & 0 & 1 & 1 & 0 & 0 & 2.14 \\
\hline 5 & 1 & 0 & 0 & 1 & 0 & 1.93 \\
\hline 6 & 0 & 0 & 0 & 0 & 0 & 2.25 \\
\hline 7 & 1 & 0 & 0 & -1 & 0 & 2.24 \\
\hline 8 & 0 & 0 & 1 & 1 & 0 & 1.84 \\
\hline 9 & 0 & 0 & 0 & 0 & 0 & 2.30 \\
\hline 10 & 0 & 0 & 0 & 1 & 1 & 2.03 \\
\hline 11 & 1 & -1 & 0 & 0 & 0 & 1.83 \\
\hline 12 & 0 & 0 & 0 & -1 & -1 & 2.02 \\
\hline 13 & 1 & 0 & -1 & 0 & 0 & 1.94 \\
\hline 14 & 0 & 0 & -1 & 0 & 1 & 1.92 \\
\hline 15 & 0 & -1 & -1 & 0 & 0 & 1.71 \\
\hline 16 & 0 & 0 & 0 & 0 & 0 & 2.41 \\
\hline 17 & -1 & 0 & 1 & 0 & 0 & 1.94 \\
\hline 18 & 0 & 0 & 1 & 0 & -1 & 1.96 \\
\hline 19 & -1 & -1 & 0 & 0 & 0 & 1.80 \\
\hline 20 & 0 & -1 & 0 & 0 & 1 & 1.91 \\
\hline 21 & 0 & -1 & 0 & 0 & -1 & 1.73 \\
\hline 22 & 0 & 0 & -1 & -1 & 0 & 1.87 \\
\hline 23 & 0 & 0 & -1 & 1 & 0 & 1.96 \\
\hline 24 & 1 & 0 & 0 & 0 & -1 & 1.96 \\
\hline 25 & 0 & 0 & 0 & 0 & 0 & 2.39 \\
\hline 26 & -1 & 0 & 0 & 0 & 1 & 1.80 \\
\hline 27 & -1 & 0 & 0 & 1 & 0 & 2.01 \\
\hline 28 & 0 & 0 & 0 & 0 & 0 & 2.38 \\
\hline 29 & 0 & 0 & 0 & 1 & -1 & 1.99 \\
\hline 30 & 0 & -1 & 0 & 1 & 0 & 1.86 \\
\hline 31 & 0 & 0 & 0 & 0 & 0 & 2.27 \\
\hline 32 & 0 & 1 & -1 & 0 & 0 & 2.09 \\
\hline 33 & -1 & 1 & 0 & 0 & 0 & 2.21 \\
\hline 34 & -1 & 0 & 0 & 0 & -1 & 2.18 \\
\hline 35 & 1 & 0 & 1 & 0 & 0 & 2.06 \\
\hline 36 & 0 & 0 & 1 & -1 & 0 & 2.18 \\
\hline 37 & -1 & 0 & 0 & -1 & 0 & 1.95 \\
\hline 38 & 0 & 0 & 0 & -1 & 1 & 2.03 \\
\hline 39 & 0 & -1 & 1 & 0 & 0 & 1.93 \\
\hline 40 & -1 & 0 & -1 & 0 & 0 & 2.00 \\
\hline 41 & 0 & 0 & 1 & 0 & 1 & 2.22 \\
\hline
\end{tabular}


Table 3. Variance analysis.

\begin{tabular}{|c|c|c|c|c|c|c|}
\hline Sources of variation & $\begin{array}{l}\text { Sum of the } \\
\text { squares }\end{array}$ & freedom & mean square & $F$ value & $P$ value & significance \\
\hline Model & 1.25 & 20 & 0.062 & 12.74 & $<0.0001$ & significant \\
\hline A-Ratio of material to solution & 0.013 & 1 & 0.013 & 2.64 & 0.1198 & \\
\hline B-distillation time & 0.230 & 1 & 0.230 & 46.94 & $<0.0001$ & $* *$ \\
\hline $\begin{array}{c}\mathrm{C} \text { - ratio of } \mathrm{NaCl} \text { dosage to } \\
\text { tobacco }\end{array}$ & 0.057 & 1 & 0.057 & 11.57 & 0.0028 & $* *$ \\
\hline D- ratio of $\mathrm{CH}_{2} \mathrm{Cl}_{2}$ to tobacco & 0.023 & 1 & 0.023 & 4.79 & 0.0407 & $*$ \\
\hline E-bath temperature & $4.159 \times 10^{-3}$ & 1 & $4.159 \times 10^{-3}$ & 0.85 & 0.3673 & \\
\hline $\mathrm{AB}$ & $1.641 \times 10^{-4}$ & 1 & $1.641 \times 10^{-4}$ & 0.034 & 0.8565 & \\
\hline $\mathrm{AC}$ & $7.227 \times 10^{-3}$ & 1 & $7.227 \times 10^{-3}$ & 1.48 & 0.2382 & \\
\hline $\mathrm{AD}$ & 0.034 & 1 & 0.034 & 6.98 & 0.0156 & $*$ \\
\hline $\mathrm{AE}$ & 0.074 & 1 & 0.074 & 15.20 & 0.0009 & $* *$ \\
\hline $\mathrm{BC}$ & $6.723 \times 10^{-3}$ & 1 & $6.723 \times 10^{-3}$ & 1.38 & 0.2547 & \\
\hline $\mathrm{BD}$ & $7.372 \times 10^{-3}$ & 1 & $7.372 \times 10^{-3}$ & 1.51 & 0.2337 & \\
\hline $\mathrm{BE}$ & 0.025 & 1 & 0.025 & 5.02 & 0.0365 & $*$ \\
\hline $\mathrm{CD}$ & 0.044 & 1 & 0.044 & 9.03 & 0.0070 & $* *$ \\
\hline CE & $6.259 \times 10^{-3}$ & 1 & $6.259 \times 10^{-3}$ & 1.28 & 0.2712 & \\
\hline $\mathrm{DE}$ & $3.242 \times 10^{-4}$ & 1 & $3.242 \times 10^{-4}$ & 0.066 & 0.7994 & \\
\hline $\mathrm{A}^{2}$ & 0.14 & 1 & 0.14 & 28.84 & $<0.0001$ & $* *$ \\
\hline $\mathrm{B}^{2}$ & 0.19 & 1 & 0.19 & 38.99 & $<0.0001$ & $* *$ \\
\hline $\mathrm{C}^{2}$ & 0.33 & 1 & 0.33 & 67.37 & $<0.0001$ & $* *$ \\
\hline $\mathrm{D}^{2}$ & 0.20 & 1 & 0.20 & 41.17 & $<0.0001$ & $* *$ \\
\hline $\mathrm{E}^{2}$ & 0.19 & 1 & 0.19 & 39.24 & $<0.0001$ & $* *$ \\
\hline Residual & 0.098 & 20 & $4.888 \times 10^{-3}$ & & & \\
\hline Lack of Fit & 0.074 & 15 & $4.966 \times 10^{-3}$ & 1.07 & 0.5150 & Not significnt \\
\hline Pure Error & 0.023 & 5 & $4.655 \times 10^{-3}$ & & & \\
\hline Cor Total & 1.34 & 40 & & & & \\
\hline
\end{tabular}

**Extremely significant, *significant

\subsubsection{Analysis of variance and fitting of two element regression equation}

Two degree polynomial regression equation between the extraction amount of flavoring substances and Non coding argument $\mathrm{A}, \mathrm{B}, \mathrm{C}, \mathrm{D}$, and $\mathrm{E}$ is as follows:

$\mathrm{R}=-60.71965+27.65816 \mathrm{~A}+8.8385 \mathrm{~B}+13.16524 \mathrm{C}+$ $22.65853 \mathrm{D}+0.6248 \mathrm{E}-1.12054 \mathrm{AB}+14.65717 \mathrm{AC}-$ $31.85183 \mathrm{AD}+2.32087 \mathrm{AE}-0.40997 \mathrm{BC}-0.65579 \mathrm{BD}-$ $0.03952 \mathrm{BE}-2.62548 \mathrm{CD}+0.03956 \mathrm{CE}+0.009 \mathrm{DE}-$ $656.38020 \mathrm{~A}^{2}-0.72025 \mathrm{~B}^{2}-5.00686 \mathrm{C}^{2}-4.02583 \mathrm{D}^{2}-$ $0.00632 \mathrm{E}^{2}$

Table 3 shows the variance analysis of the above regression model. As shown in Table 3 , the $\mathrm{F}$ value of this model was $12.74, \mathrm{p}<0.01$, suggesting this model was extremely significant. The coefficient of determination of this regression model was $\mathrm{R}^{2}=0.9272$. Loss of fitting $\mathrm{F}$ value was $1.07, p>0.05$, and the loss of fitting is insignificant, indicating the fitting of regression equation in the whole regression region is good, which suggests this model can describe the results well. Thus, this model can be applied to analyze and predict the extraction of extraction amount of flavoring substances.

\subsection{Analysis of interaction}

Two regression models were used to standardize the analysis, and the shape of the response surface was investigated to more directly show the effect of two factors on the extraction of flavoring substances.
The interactional factors affecting the results were $A D$, $\mathrm{AE}, \mathrm{BE}$ and $\mathrm{CD}$, and their influences on the extraction of flavoring substances were investigated and shown in Figure 8 .

As shown in Figure 8, when the distillation time was 3 $\mathrm{h}$, the ratio of $\mathrm{NaCl}$ dosage to tobacco was $1: 1$, and bath temperature was $60{ }^{\circ} \mathrm{C}$, the impact of the combined the ratio of material to solution and the ratio of $\mathrm{CH}_{2} \mathrm{Cl}_{2}$ to tobacco on the the extraction of flavoring substances is significant. Because the the shape of contour can reflect the extent of the interaction effect, thus this indicated properly reduction of the ratio of material to liquid can enhance the extraction of flavoring substances, and reduce the consumption of $\mathrm{CH}_{2} \mathrm{Cl}_{2}$

Figure 9 presents the response surface and contour plot of the interaction between the ratio of material to liquid and temperature. It was found that when the distillation time was $3 \mathrm{~h}$, the ratio of $\mathrm{NaCl}$ dosage to tobacco was 2:1, and the ratio of $\mathrm{CH}_{2} \mathrm{Cl}_{2}$ to tobacco was $2: 1$, the impact of the combined the ratio of material to solution and the bath temperature on the the extraction of flavoring substances is significant. When the ratio of material to solution increased, the flavoring substances in the volatile aqueous phase reduced in a unit time period, which could promote extraction, thereby causing more extraction of flavoring substances. However, when the bath temperature was at low level, increase of ratio of material to solution could cause the higher volatilization of water than $\mathrm{CH}_{2} \mathrm{Cl}_{2}$, which posed a negative impact on extraction extent. It should be noted that when the ratio of material to solution was controlled, the extraction of flavoring substances would show the trend of first increase and then decrease, suggesting the single factor 
i.e., the ratio of material to solution and bath temperature affected the extraction of flavoring substances

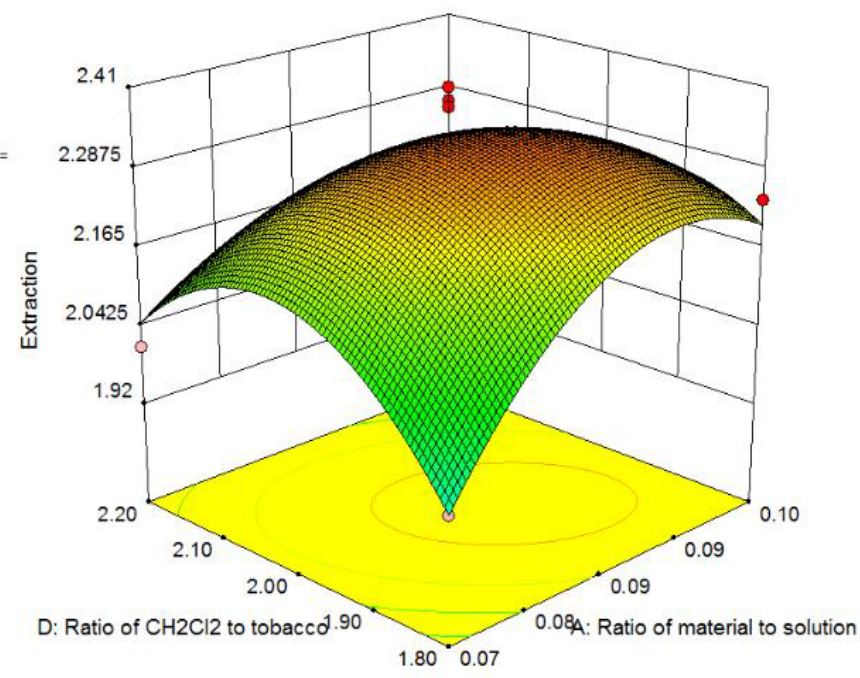

Figure 8. Response surface and contour map of $\mathrm{R}=\mathrm{f}(\mathrm{A}, \mathrm{D})$.

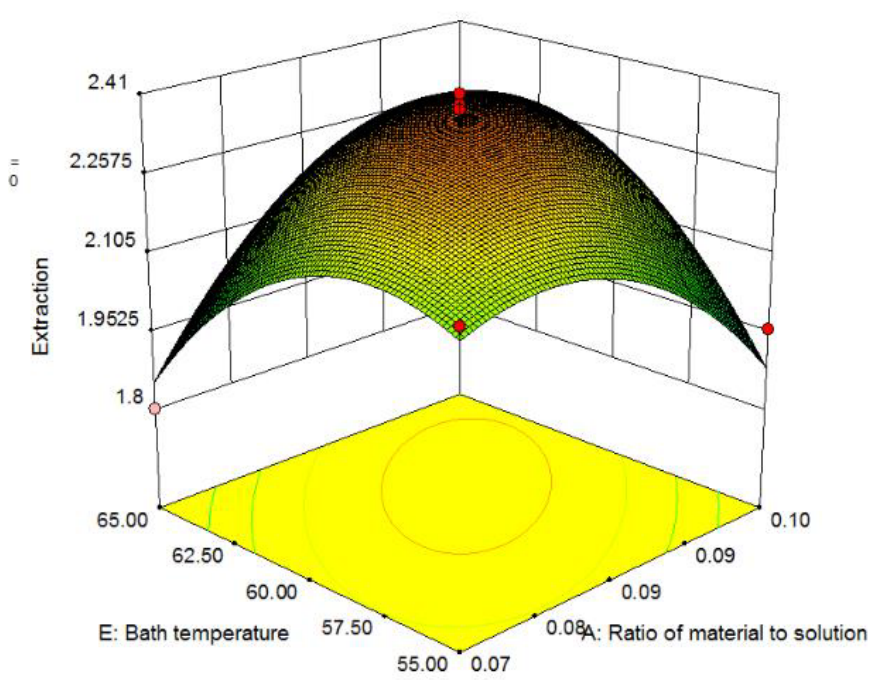

Figure 9. Response surface and contour map of $R=f(A, E)$.

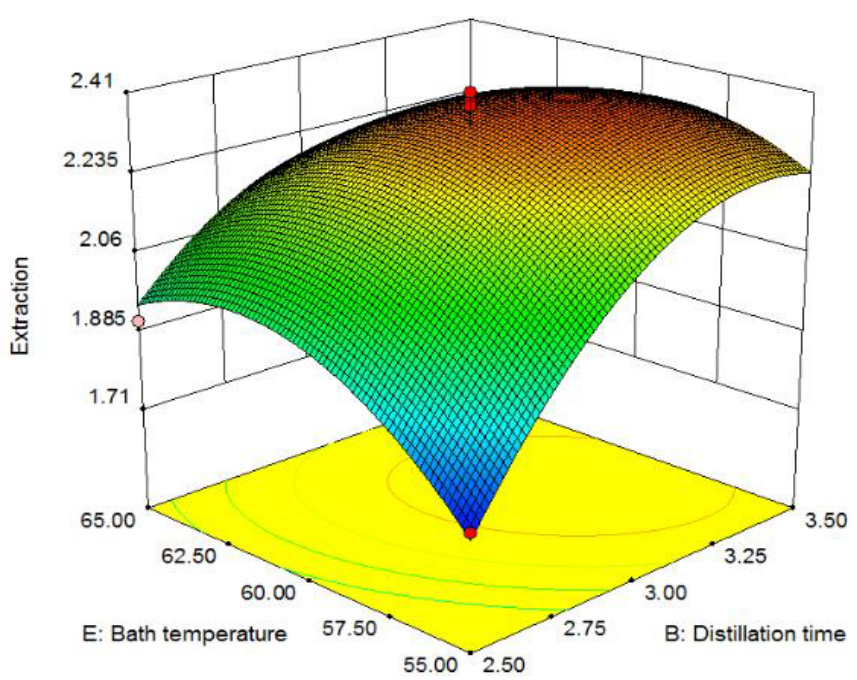

Figure 10. Response surface and contour map of $R=f(B, E)$. insignificantly.
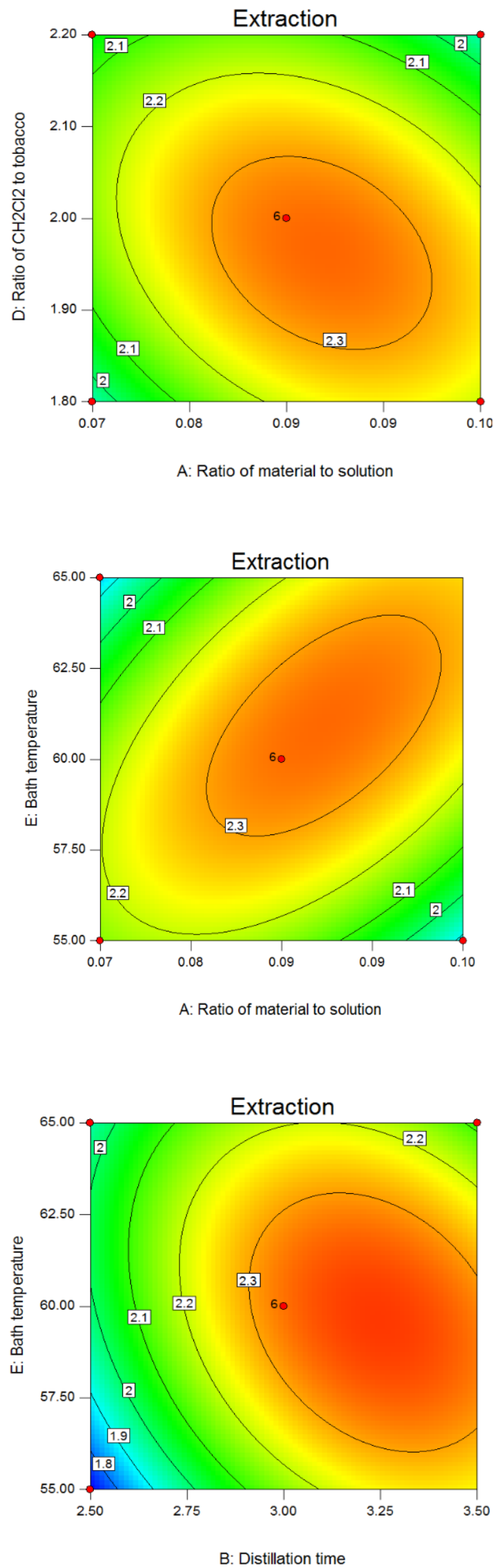

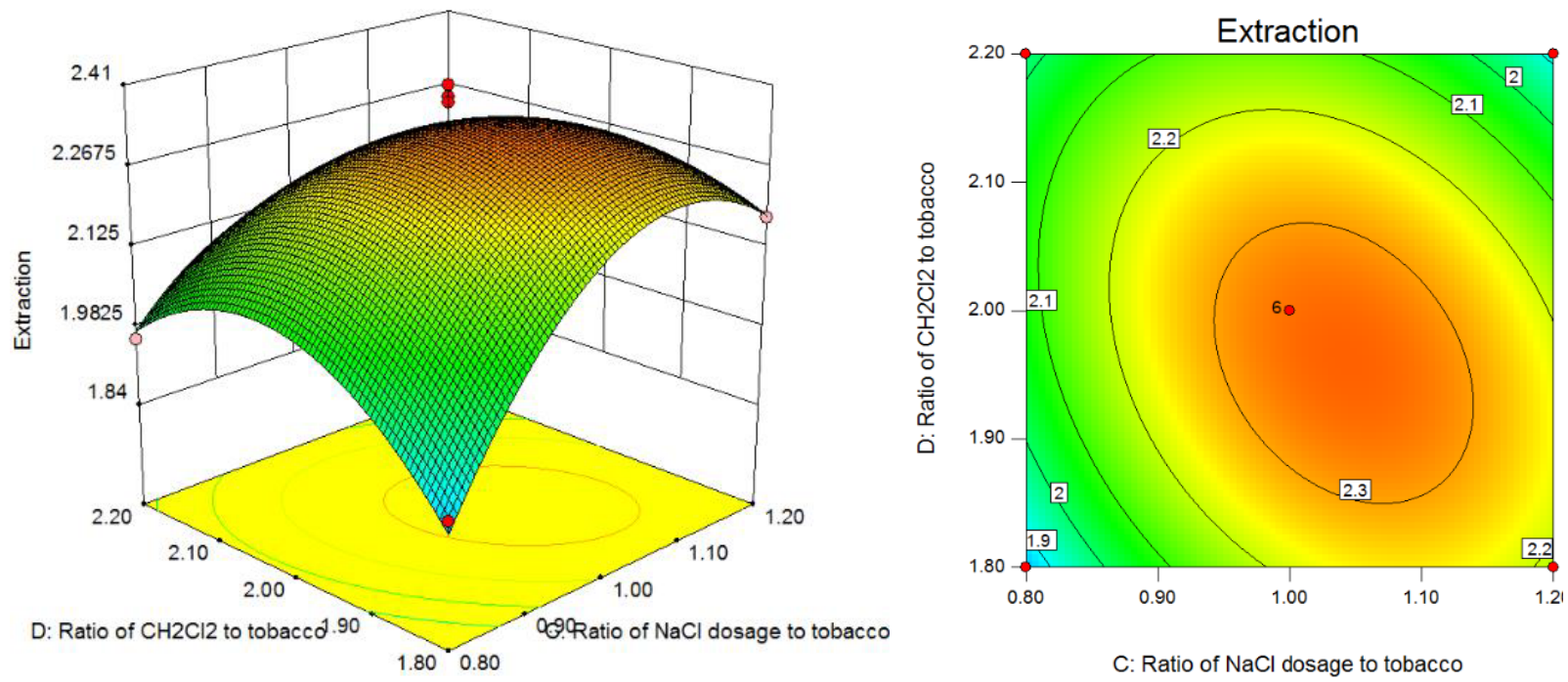

Figure 11. Response surface and contour map of $R=f(C, D)$.

Figure 10 presents the response surface and contour plot of the interaction between the distillation time and bath temperature. It can be found that when the ratio of material to liquid was $1: 12$, the ratio of $\mathrm{NaCl}$ dosage to tobacco was $2: 1$, and the ratio of $\mathrm{CH}_{2} \mathrm{Cl}_{2}$ to tobacco was $2: 1$, the combined effect of distillation time and bath temperature on the the extraction of flavoring substances is significant. From this part, it can get the selection of appropriate bath temperature is conducive to the increase of the amount of extraction of aroma substances, and can reduce the time of distillation and extraction.

The response surface and contour plot of the interaction between the ratio of $\mathrm{NaCl}$ dosage to tobacco and ratio of $\mathrm{CH}_{2} \mathrm{Cl}_{2}$ to tobacco is shown in Figure 11. When the ratio of material to liquid was $1: 12$, distillation time was controlled at $3 \mathrm{~h}$, bath temperature was maintained at $60{ }^{\circ} \mathrm{C}$, the combined effect of the ratio of $\mathrm{NaCl}$ dosage to tobacco and the ratio of $\mathrm{CH}_{2} \mathrm{Cl}_{2}$ to tobacco on the the extraction of flavoring substances is significant. As shown in Figure 11, when the ratio of $\mathrm{CH}_{2} \mathrm{Cl}_{2}$ to tobacco is in a certain range, the increase of $\mathrm{NaCl}$ dosage to tobacco could promote the extraction of flavoring substances. Also, it can be found that the increase of $\mathrm{NaCl}$ could enhance the extraction of flavoring substances.

In summary, this model is stable, and the optimal results obtained from response surface analysis of the regression model are as follows: the ratio of material to liquid was $1: 12$, the distillation time was $3.23 \mathrm{~h}$, the ratio of $\mathrm{NaCl}$ dosage to tobacco was $1.05: 1$, the ratio of $\mathrm{CH}_{2} \mathrm{Cl}_{2}$ to tobacco was 1.92 , the bath temperature was $60{ }^{\circ} \mathrm{C}$, and the amount of extraction of flavoring substances was 2.39 $\mathrm{mg} / \mathrm{g}$.

\section{Conclusions}

This work investigated the optimum operating conditions for SDE using RSM, and further investigate extraction efficiency and stability under the operating conditions. Results showed that the optimal results obtained from response surface analysis of the regression model are as follows: the ratio of material to liquid was $1: 12$, the distillation time was $3.23 \mathrm{~h}$, the ratio of $\mathrm{NaCl}$ dosage to tobacco was $1.05: 1$, the ratio of $\mathrm{CH}_{2} \mathrm{Cl}_{2}$ to tobacco was 1.92, the bath temperature was $60{ }^{\circ} \mathrm{C}$, and the amount of extraction of flavoring substances was $2.39 \mathrm{mg} / \mathrm{g}$. This study will provide a theoretical basis for detection of tobacco flavor components.

\section{Acknowledgements}

This research was financially supported by the project of Science research and technology development of China National Tobacco Corp (110200701009), The Guangxi Zhuang Autonomous Region technology innovation project (The GUI technology [2016]181)

\section{References}

1. D. Hoffmann, I. Hoffmann, K. El-Bayoumy, The less harmful cigarette: a controversial issue. A tribute to Ernst L. Wynder. Chemical research in toxicology. 14(7), 767-790 (2001).

2. R.A Dixon, Engineering of plant natural product pathways. Current opinion in plant biology. 8(3), 329-336 (2005).

3. D.M. Jahin, Current and future trends in the automotive industry. J. Mech. Eng. Res. Dev. 39 (1), 97-100 (2016).

4. S.R. Rivellino, L.W. Hantao, S. Risticevic, et al., Detection of extraction artifacts in the analysis of honey volatiles using comprehensive two-dimensional gas chromatography. Food chemistry. 141(3), 1828-1833 (2013).

5. S.B. Ge, J. Tao, L.S. Wang, W.X. Peng, D.L. Li, Y.Z. Furuta, TD-GC-MS Analysis on Antibacterial and Safety Characteristics of Volatiles from Bamboo during Cavitation, Carbonization and Activation for Public Health. Journal of Pure and Applied Microbiology. 9 (3), 1907-1912 (2015).

6. L. Du, J. Li, W. Li, et al., Characterization of volatile compounds of pu-erh tea using solid-phase 
microextraction and simultaneous distillation-extraction coupled with gas chromatography-mass spectrometry. Food Research International. 57, 61-70 (2014).

7. L. Wang, Y.Q. Wang, et al., Mechanism of pavement compaction detection technology to improve the quality of pavement construction. J. Mech. Eng. Res. Dev. 39(1), 112-118 (2016).

8. P.J. Watkins, G. Rose, R.D. Warner, et al., A comparison of solid-phase microextraction (SPME) with simultaneous distillation-extraction (SDE) for the analysis of volatile compounds in heated beef and sheep fats. Meat science. 91(2), 99-107 (2012).

9. R.L. Mason, R.F. Gunst, J.L. Hess. Statistical design and analysis of experiments: with applications to engineering and science. John Wiley \& Sons, (2003).

10. E.I. Taha, A.M. Samy, A.A. Kassem, et al., Response surface methodology for the development of self-nanoemulsified drug delivery system (SNEDDS) of all-trans-retinol acetate. Pharmaceutical Development \& Technology. 10(3), 363-370 (2008).
11. D.C. Mccrory, R.R. Coeytaux, W.S.Y. Jr, et al., Response Surface Methodology: Process and Product Optimization Using Designed Experiments / R.H. Myers, D.C. Montgomery. Cer, (2013).

12. J. Zhao, D. Wang, X. Li, et al., Free nitrous acisd serving as a pretreatment method for alkaline fermentation to enhance short-chain fatty acid production from waste activated sludge. Water Research. 78, 111-120 (2015).

13. J. Zhao, Y. Liu, B. Ni, et al., Combined Effect of Free Nitrous Acid Pretreatment and Sodium Dodecylbenzene Sulfonate on Short-Chain Fatty Acid Production from Waste Activated Sludge. Scientific Reports. 6, 2016.

14. Z.L. Liu, Fractal theory and application in city size distribution. Information Technology Journals. 12(17), 4158-4162 (2013).

15. L.F. Huang, M.J. Wu, K.J. Zhong, et al., Fingerprint developing of coffee flavor by gas chromatography-mass spectrometry and combined chemometrics methods. Analytica Chimica Acta. 588(2), 216-223 (2007). 